\title{
Author Correction: Cellular senescence and Alzheimer disease: the egg and the chicken scenario
}

\section{Sara Saez-Atienzar iD and Eliezer Masliah iD}

Nature Reviews Neuroscience (2020) https://doi.org/10.1038/s41583-020-0325-z Published online 29 June 2020

The originally published article referred to retinoblastoma or RB 'hyperphosphorylation' three times in the legend for Figure 2 and once in the main text (in the section headed 'Cellular senescence mechanisms'), which was incorrect. The text should have read retinoblastoma or RB 'hypophosphorylation'. This has been corrected in the HTML and PDF versions of the manuscript.

https://doi.org/10.1038/s41583-020-0366-3 I Published online 13 August 2020

This is a U.S. government work and not under copyright protection in the U.S.; foreign copyright protection may apply 2020 